\title{
Incidence and risk factors for preoperative deep venous thrombosis in 314 consecutive patients undergoing surgery for spinal metastasis
}

\author{
Brad E. Zacharia, MD, MS, ${ }^{1}$ Sweena Kahn, MS, ${ }^{1}$ Evan D. Bander, MD, ${ }^{2}$ Gustav Y. Cederquist, BA, ${ }^{2}$ \\ William P. Cope, BS, ${ }^{2}$ Lily McLaughlin, BS, ${ }^{1}$ Alexa Hijazi, ${ }^{1}$ Anne S. Reiner, MPH, ${ }^{3}$ Ilya Laufer, MD, ${ }^{1}$ \\ and Mark Bilsky, MD'1
}

Departments of ${ }^{1}$ Neurosurgery and ${ }^{3}$ Epidemiology \& Biostatistics, Memorial Sloan Kettering Cancer Center; and ${ }^{2}$ Department of Neurological Surgery, Weill Cornell Medical College, New York, New York

OBJECTIVE The authors of this study aimed to identify the incidence of and risk factors for preoperative deep venous thrombosis (DVT) in patients undergoing surgical treatment for spinal metastases.

METHODS Univariate analysis of patient age, sex, ethnicity, laboratory values, comorbidities, preoperative ambulatory status, histopathological classification, spinal level, and surgical details was performed. Factors significantly associated with DVT univariately were entered into a multivariate logistic regression model.

RESULTS The authors identified 314 patients, of whom $232(73.9 \%)$ were screened preoperatively for a DVT. Of those screened, $22(9.48 \%)$ were diagnosed with a DVT. The screened patients were older (median 62 vs 55 years, $p=$ 0.0008 ), but otherwise similar in baseline characteristics. Nonambulatory status, previous history of DVT, lower partial thromboplastin time, and lower hemoglobin level were statistically significant and independent factors associated with positive results of screening for a DVT. Results of screening were positive in only $6.4 \%$ of ambulatory patients in contrast to $24.4 \%$ of nonambulatory patients, yielding an odds ratio of $4.73(95 \% \mathrm{Cl} 1.88-11.90)$. All of the patients who had positive screening results underwent preoperative placement of an inferior vena cava filter.

CONCLUSIONS Patients requiring surgery for spinal metastases represent a population with unique risks for venous thromboembolism. This study showed a $9.48 \%$ incidence of DVT in patients screened preoperatively. The highest rates of preoperative DVT were identified in nonambulatory patients, who were found to have a 4-fold increase in the likelihood of harboring a DVT. Understanding the preoperative thrombotic status may provide an opportunity for early intervention and risk stratification in this critically ill population.

https://thejns.org/doi/abs/10.3171/2017.2.SPINE16861

KEY WORDS deep venous thrombosis; pulmonary embolism; spinal metastasis; oncology

$\mathrm{C}$ ANCER patients are at significantly increased risk for the development of venous thromboembolism (VTE), including deep venous thrombosis (DVT) and pulmonary embolism (PE). ${ }^{33}$ When a VTE does occur, cancer patients suffer increased rates of morbidity and mortality compared with patients without cancer, and the costs and risks of treatment are significant. ${ }^{9,11,13,35,42}$ These factors combine to provide a strong rationale for prevention.
Overall, 30\% of cancer patients will develop metastatic spinal disease, resulting in significant pain and neurological impairment, which together serve to further increase the risk of VTE. ${ }^{5,6,39}$ While the effects of surgery on VTE risk are multiplicative, surgical decompression of the spine is an effective approach to palliate cancer-related symptoms and improve quality of life..$^{25,32}$

The reported rates of postoperative VTE range from $1.5 \%$ to $10 \% .^{11,38,39}$ Cancer increases the risk of $\mathrm{VTE}^{26,28}$

ABBREVIATIONS BMI = body mass index; DVT = deep venous thrombosis; IQR = interquartile range; IVC = inferior vena cava; $P E=$ pulmonary embolism; VTE = venous thromboembolism.

SUBMITTED July 22, 2016. ACCEPTED February 9, 2017.

INCLUDE WHEN CITING Published online June 2, 2017; DOI: 10.3171/2017.2.SPINE16861. 
and places patients with spinal metastases at particularly high risk. Despite the fact that these patients are among the most vulnerable to the development of VTE, the preoperative baseline VTE risk, underlying risk factors for VTE, and the guidelines for prevention and prophylaxis are not well defined in this population..$^{8,38}$ To this end, we analyzed our institutional series to estimate the incidence of and risk factors for preoperative DVT among cancer patients with spinal metastases who underwent spinal surgery at our institution. As a secondary goal, we examined the impact of a routine preoperative DVT screening protocol on the development of postoperative VTE.

\section{Methods \\ Patient Selection}

The surgical database of the Department of Neurosurgery at Memorial Sloan Kettering Cancer Center was used to retrospectively identify a consecutive series of patients who underwent spinal surgery at that institution between January 2012 and December 2014. Only those patients with histologically confirmed metastatic spinal disease were included in the study. No patient was excluded on the basis of prior history of DVT or PE. A total of 314 consecutive patients were identified who fulfilled these criteria. The study was approved by the institutional review board of Memorial Sloan Kettering Cancer Center.

\section{Standard VTE Protocol}

Preoperative ultrasonographic screening for DVT was routinely performed during the study period. Patients in which this screening was positive typically underwent preoperative placement of an inferior vena cava (IVC) filter, which was performed with the intention of mitigating postoperative PE risk. In addition to IVC filter placement a concerted effort was made to initiate mechanical (in patients without DVT) and/or pharmacological prophylaxis on postoperative Day 1 in all patients. Routine postoperative VTE screening was not performed in this population. We did, however, maintain a low threshold for screening in the event of symptoms suggestive of a DVT and/or PE.

\section{Study Variables}

A retrospective chart review of medical/surgical oncology, pathology, and radiology records was performed. Demographic data were collected on age and body mass index (BMI) at surgery, sex, and ethnicity. Data on relevant medical comorbidities were recorded for factors known to be associated with VTE risk, including ambulatory status, selected laboratory test results, tobacco history, diabetes mellitus, and hypertension. Ambulatory status was abstracted from the most recent medical records within 30 days prior to surgery, and was based on neurological examination accounts of gait, ambulatory status, or descriptions of activities of daily living. The criterion for ambulatory status was defined as any amount of walking preoperatively. Previous history of VTE was obtained from medical records and categorized into recent history of DVT ( $<6$ months), distant history of DVT ( $>6$ months), and any history of PE. Tumor characteristics were collected, including his- topathological classification and spinal level. Preoperative clinical data regarding DVT screening, including Doppler ultrasound results, symptomatology, and IVC filter placement, were collected. Surgical data were recorded, including estimated blood loss, type of spinal surgery, emergency status, number of vertebral segments operated on, and duration of surgery. Postoperative data were recorded on DVT diagnosis, PE diagnosis, length of stay, disposition at discharge, vital status, date of death, and date of last follow-up. The primary endpoint evaluated was preoperative DVT diagnosis from Doppler ultrasound screening.

\section{Statistical Analysis}

Descriptive statistics (medians, means, standard deviations, frequencies, and ranges) were used to characterize the cohort. Categorical variables were compared in those with and without DVT using the chi-square test and the Fisher exact test where appropriate. Similarly, continuous variables were compared using the Student $\mathrm{t}$-test and the Wilcoxon rank-sum test where appropriate. Factors significantly associated with DVT on univariate analysis were entered into a multivariate logistic regression model. All $\mathrm{p}$ values were 2 -sided, with values $<0.05$ considered statistically significant. All statistical analyses were performed in SAS (version 9.4, SAS Institute Inc.).

\section{Results}

\section{Patient Demographics}

We identified 314 consecutive patients undergoing surgery for spinal metastasis at our institution from January 2012 through December 2014. The median age for the overall study population was 60 years (range 16-92 years; Table 1). The majority of patients (89\%) underwent posterolateral decompression with posterior instrumented fusion while the remaining underwent percutaneous instrumented stabilization (8\%) or resection without fixation (3\%). The median duration of surgery was 163 minutes and the median length of hospital stay for the procedure was 7 days (interquartile range [IQR] 5-11 days). Preoperatively, 40 patients (12.7\%) had a history of recent or distant DVT or PE, and 4 patients $(1.3 \%)$ had a history of both DVT and PE. At the time of admission, 52 patients (16.6\%) were nonambulatory. All patients in this study underwent standard VTE prophylaxis postoperatively including Venodyne boots (Ecolab) and $30 \mathrm{mg}$ enoxaparin twice daily.

\section{Comparison of Screened Versus Unscreened Population}

As compared with the unscreened group, screened patients were older (mean age 60 vs 53 years, $p=0.0008$ ) with lower hemoglobin levels (mean $11.3 \mathrm{vs} 11.9 \mathrm{~g} / \mathrm{dl}, \mathrm{p}=$ $0.02)$ and a higher white blood cell count $\left(9.3\right.$ vs $7.4 \times 10^{9}$ cells $/ L, p=0.02)$. Yet, the unscreened and screened groups were otherwise well matched on baseline demographic and clinical factors including sex, race, ambulatory status, BMI, pathology, and medical comorbidities (Table 2).

\section{Sensitivity Analysis}

Since not all patients underwent preoperative screening 
TABLE 1. Summary of patient characteristics

\begin{tabular}{|c|c|}
\hline Characteristic & Value \\
\hline Total no. of patients & 314 \\
\hline \multicolumn{2}{|l|}{ Age in yrs } \\
\hline Median & 60 \\
\hline Range & $16-92$ \\
\hline \multicolumn{2}{|l|}{ Sex } \\
\hline Female & $132(42)$ \\
\hline Male & $182(58)$ \\
\hline \multicolumn{2}{|l|}{ Race } \\
\hline White & $247(78.7)$ \\
\hline Black & $31(9.9)$ \\
\hline Hispanic & $4(1.3)$ \\
\hline Asian & $16(5.1)$ \\
\hline Unknown & $10(3.2)$ \\
\hline \multicolumn{2}{|l|}{ Comorbidities } \\
\hline \multicolumn{2}{|l|}{$\mathrm{BMl}$ in $\mathrm{kg} / \mathrm{m}^{2}$} \\
\hline$<25$ & $136(43.3)$ \\
\hline 25 to $<30$ & $102(32.5)$ \\
\hline$\geq 30$ & $73(23.2)$ \\
\hline Unknown & $3(0.96)$ \\
\hline Diabetes mellitus & $42(13.4)$ \\
\hline \multicolumn{2}{|l|}{ Tobacco use } \\
\hline Never & $149(47.5)$ \\
\hline Former & $145(46.2)$ \\
\hline Current & $20(6.4)$ \\
\hline Hypertension & $151(48.1)$ \\
\hline LE fracture & $24(7.6)$ \\
\hline \multicolumn{2}{|l|}{ Prior DVT/PE } \\
\hline None & $270(86)$ \\
\hline DVT w/in 6 mos & $12(3.8)$ \\
\hline DVT >6 mos & $16(5.1)$ \\
\hline PE & $12(3.8)$ \\
\hline DVT \& PE & $4(1.3)$ \\
\hline \multicolumn{2}{|l|}{ Preoperative } \\
\hline \multicolumn{2}{|l|}{ Ambulatory status } \\
\hline No & $52(16.6)$ \\
\hline Yes & $262(83.4)$ \\
\hline \multicolumn{2}{|l|}{ DVT } \\
\hline Symptomatic & $58(18.5)$ \\
\hline Doppler US screened & $232(73.9)$ \\
\hline DVT diagnosed & $22(7.01)$ \\
\hline IVC filter placed & 41 (13.1) \\
\hline \multicolumn{2}{|l|}{ Tumor pathology } \\
\hline NSCLC & $60(19.1)$ \\
\hline $\mathrm{RCC}$ & $39(12.4)$ \\
\hline Sarcoma & $30(9.6)$ \\
\hline Breast & $29(9.2)$ \\
\hline Prostate & $29(9.2)$ \\
\hline Melanoma & $15(4.8)$ \\
\hline Colorectal & $14(4.5)$ \\
\hline
\end{tabular}

CONTINUED IN NEXT COLUMN »
» CONTINUED FROM PREVIOUS COLUMN

TABLE 1. Summary of patient characteristics

\begin{tabular}{|c|c|}
\hline Characteristic & Value \\
\hline \multicolumn{2}{|l|}{ Tumor pathology (continued) } \\
\hline Carcinoma, other & $59(18.8)$ \\
\hline Unknown & $12(3.8)$ \\
\hline Other & $26(8.3)$ \\
\hline \multicolumn{2}{|l|}{ Spinal level } \\
\hline Cervical & $52(16.6)$ \\
\hline Thoracic & $172(54.8)$ \\
\hline Lumbar & $80(25.5)$ \\
\hline Sacral & $1(0.3)$ \\
\hline \multicolumn{2}{|l|}{ Surgical details } \\
\hline \multicolumn{2}{|c|}{ Time from screening to surgery in days } \\
\hline Median & 2 \\
\hline IQR & $1-5$ \\
\hline \multicolumn{2}{|l|}{ Type of surgery } \\
\hline Decompression, fusion & $224(71.3)$ \\
\hline Decompression, no fusion & $54(17.2)$ \\
\hline Percutaneous screw fixation & $34(10.8)$ \\
\hline \multicolumn{2}{|l|}{ Estimated blood loss in $\mathrm{ml}$} \\
\hline Median & 500 \\
\hline Range & $0-3400$ \\
\hline \multicolumn{2}{|l|}{ Duration of surgery, hrs:mins } \\
\hline Median & $2: 43$ \\
\hline Range & $3: 29-12: 40$ \\
\hline \multicolumn{2}{|l|}{ Postoperative } \\
\hline DVT diagnosis & $13(4.1)$ \\
\hline PE diagnosis & $4(1.3)$ \\
\hline \multicolumn{2}{|l|}{ Length of stay in days } \\
\hline Median & 7 \\
\hline Range & $0-740$ \\
\hline
\end{tabular}

$\mathrm{LE}=$ lower extremity; NSCLC = non-small cell lung cancer; RCC = renal cell carcinoma; US = ultrasound.

Data are numbers of patients (\%) unless otherwise indicated.

and there was some suggestion of a selection bias (noted above), we performed a rough sensitivity analysis to provide a range for the preoperative DVT incidence in this population. If all patients who did not undergo screening truly did not have a DVT, the preoperative incidence would be $7 \%$ (22/314). On the other hand, if all patients in the unscreened cohort did have a preoperative DVT the incidence would be $33.12 \%$ (104/314). One can surmise that the true incidence of preoperative DVT in this population was between $7 \%$ and $33.12 \%$.

\section{Preoperative Management of DVT}

Preoperative screening for DVT was performed in 232 patients $(73.9 \%)$. Of those screened, DVT was identified in 22 patients $(9.48 \%)$. Among the 58 patients who were symptomatic preoperatively, $48(82.75 \%)$ were screened. Of these, DVT was identified in 5 patients $(10.42 \%)$. The median time from preoperative ultrasonographic screen- 
TABLE 2. Comparison of demographic and clinical characteristics between screened and unscreened patients

\begin{tabular}{|c|c|c|c|}
\hline Characteristic & Screened & Unscreened & $p$ Value \\
\hline Sex & & & 0.69 \\
\hline Male & $136(59)$ & $46(56)$ & \\
\hline Female & $96(41)$ & $36(44)$ & \\
\hline Age in yrs, mean & $60.1 \pm 13.5$ & $53.3 \pm 16.1$ & 0.0008 \\
\hline Race & & & 0.54 \\
\hline White & $180(78)$ & $67(82)$ & \\
\hline Black & $24(10)$ & $7(9)$ & \\
\hline Hispanic & $2(1)$ & $2(2)$ & \\
\hline Asian & $12(5)$ & $4(5)$ & \\
\hline Other or unknown & $14(6)$ & $2(2)$ & \\
\hline Ambulatory & & & 0.37 \\
\hline No & $41(18)$ & $11(13)$ & \\
\hline Yes & $191(82)$ & $71(87)$ & \\
\hline $\mathrm{BMI}$ in $\mathrm{kg} / \mathrm{m}^{2}$ & & & 0.25 \\
\hline$<25$ & $96(42)$ & $42(51)$ & \\
\hline 25 to $<30$ & $80(35)$ & $21(26)$ & \\
\hline$\geq 30$ & $53(23)$ & $19(23)$ & \\
\hline Unknown & 3 & & \\
\hline Diabetes & & & 0.71 \\
\hline No & $200(86)$ & $72(88)$ & \\
\hline Yes & $32(14)$ & $10(12)$ & \\
\hline Tobacco use & & & 0.06 \\
\hline Never & $101(44)$ & $48(59)$ & \\
\hline Former & $116(50)$ & $29(35)$ & \\
\hline Current & $15(6)$ & $5(6)$ & \\
\hline Hypertension & & & 0.16 \\
\hline No & $115(50)$ & $48(59)$ & \\
\hline Yes & $117(50)$ & $34(41)$ & \\
\hline LE fracture & & & 0.72 \\
\hline No & 215 & 75 & \\
\hline Yes & 17 & 7 & \\
\hline Pathology & & & 0.42 \\
\hline Breast & $21(10)$ & $8(10)$ & \\
\hline Prostate & $24(11)$ & $5(6)$ & \\
\hline Colorectal & $8(4)$ & $6(7)$ & \\
\hline NSCLC & $46(21)$ & $14(17)$ & \\
\hline Other* & $121(55)$ & $49(60)$ & \\
\hline Unknown & 12 & & \\
\hline History of DVT/PE & & & 0.86 \\
\hline No & $199(86)$ & $71(87)$ & \\
\hline Yes & $33(14)$ & $11(13)$ & \\
\hline Hemoglobin, g/dl, mean & $11.3 \pm 1.8$ & $11.9 \pm 1.8$ & 0.02 \\
\hline WBC count, $\times 10^{9} / \mathrm{L}$, mean & $9.3 \pm 7.7$ & $7.4 \pm 3.4$ & 0.02 \\
\hline PT in seconds, mean & $12.2 \pm 3.6$ & $11.7 \pm 2.1$ & 0.14 \\
\hline Platelets, $\times 10^{9} / \mathrm{L}$, mean & $273.1 \pm 127.0$ & $263.5 \pm 138.4$ & 0.57 \\
\hline PTT in seconds, mean & $28.7 \pm 4.6$ & $28.9 \pm 4.9$ & 0.68 \\
\hline
\end{tabular}

CONTINUED IN NEXT COLUMN »
» CONTINUED FROM PREVIOUS COLUMN

TABLE 2. Comparison of demographic and clinical characteristics between screened and unscreened patients

PT = prothrombin time; $\mathrm{WBC}=$ white blood cell.

Data are numbers of patients (\%) unless otherwise indicated. Means are presented with SDs.

* Other pathologies include melanoma, renal cell, thyroid, sarcoma, heme, neuroblastoma, neuroendocrine, and other (not otherwise specified [NOS]).

ing to surgery was 2 days (IQR $1-5$ days). Factors statistically associated with positive DVT screening included nonambulatory status, previous history of DVT or PE, lower partial thromboplastin time (PTT), and lower hemoglobin level (Table 3). Histology was not associated with an increased incidence of VTE. Additionally, multivariate analysis revealed that these factors were all independently associated with positive DVT screening (Table 4). While only $6.4 \%$ of ambulatory patients had positive screening results, $24.4 \%$ of nonambulatory patients had positive results, yielding an odds ratio of 4.73 (95\% CI 1.88-11.90). Forty-one patients (33 screened and 8 unscreened) underwent placement of IVC filters prior to surgery. Thirty-three of these patients had newly diagnosed DVT on screening ultrasound. The remaining 8 had a known history of DVT/ $\mathrm{PE}$, with 3 patients having had IVC filters already in place prior to presurgical evaluation and the remaining $5 \mathrm{pa}-$ tients having had IVC filters placed as part of preoperative preparation. Complications from IVC filter placement occurred in 1 patient. In this patient, CT imaging revealed a clot below and at the tip of the filter 3 weeks after infrarenal IVC filter placement. Patients with current and former tobacco use accounted for $64 \%$ of those who had positive results on preoperative screening for DVT.

\section{Postoperative DVT/PE}

Within the 30-day postoperative period, there were 5 patient deaths and DVT was identified in 13 patients (4.1\%). Nine of these 13 patients had undergone preoperative ultrasonographic screening with negative results. Two of these patients had a distant history ( $>6$ months prior to surgery) of DVT. Of the 13 patients who developed postoperative DVT, 12 were ambulatory preoperatively.

Additionally, 4 patients (1.3\%) developed postoperative PE. Each of these 4 patients underwent preoperative ultrasonographic screening, and all were ambulatory pre- and postoperatively. Of these 4 patients, 2 had an IVC filter in place prior to surgery due to either a distant history of PE $(n=1)$ or a positive preoperative screening for DVT $(n=$ 1). One patient developed PE in the setting of a newly diagnosed lung abscess. The remaining 3 patients presented with dyspnea, mild hypoxia, and/or tachycardia. All PEs were treated with either IVC placement and/or anticoagulation therapy.

\section{Discussion}

\section{Incidence of DVT}

We present the first clinical study reporting the incidence and risk factors of preoperative DVT in the highrisk group of patients diagnosed with spinal metastases. 
TABLE 3. Comparing characteristics of those with and without preoperative DVT in the screened population

\begin{tabular}{|c|c|c|c|}
\hline Characteristic & DVT & No DVT & $\mathrm{p}$ Value \\
\hline Sex & & & 0.38 \\
\hline Male & $15(68)$ & $121(58)$ & \\
\hline Female & $7(32)$ & $86(42)$ & \\
\hline Age in yrs, mean & $61.5 \pm 12.0$ & $60.1 \pm 13.6$ & 0.64 \\
\hline Race & & & 0.60 \\
\hline White & $19(86)$ & $159(77)$ & \\
\hline Black & $3(14)$ & $21(10)$ & \\
\hline Hispanic & $0(0)$ & $2(1)$ & \\
\hline Asian & $0(0)$ & $11(5)$ & \\
\hline Other or unknown & $0(0)$ & $14(7)$ & \\
\hline Ambulatory & & & 0.002 \\
\hline No & $10(45)$ & $31(15)$ & \\
\hline Yes & $12(55)$ & $176(85)$ & \\
\hline BMl in $\mathrm{kg} / \mathrm{m}^{2}$ & & & 0.93 \\
\hline$<25$ & $8(38)$ & $86(42)$ & \\
\hline 25 to $<30$ & $8(38)$ & $71(35)$ & \\
\hline$\geq 30$ & $5(24)$ & $48(23)$ & \\
\hline Unknown & 1 & 2 & \\
\hline Diabetes & & & 0.21 \\
\hline No & $17(77)$ & $180(87)$ & \\
\hline Yes & $5(23)$ & $27(13)$ & \\
\hline Tobacco use & & & 0.34 \\
\hline Never & $8(36)$ & $92(44)$ & \\
\hline Former & $11(50)$ & $103(50)$ & \\
\hline Current & $3(14)$ & $12(6)$ & \\
\hline Hypertension & & & 0.95 \\
\hline No & $11(50)$ & $102(49)$ & \\
\hline Yes & $11(50)$ & $105(51)$ & \\
\hline Pathology & & & 0.41 \\
\hline Breast & $0(0)$ & $20(10)$ & \\
\hline Prostate & $4(19)$ & $20(10)$ & \\
\hline Colorectal & $0(0)$ & $7(4)$ & \\
\hline NSCLC & $5(24)$ & $40(20)$ & \\
\hline Other* & $12(57)$ & $109(56)$ & \\
\hline Unknown & 1 & 11 & \\
\hline History of DVT/PE & & & 0.0009 \\
\hline No & $13(59)$ & $184(89)$ & \\
\hline Yes & $9(41)$ & $23(11)$ & \\
\hline Screened & & & 0.18 \\
\hline No & $2(8)$ & $57(22)$ & \\
\hline Yes & $22(92)$ & $207(78)$ & \\
\hline Hemoglobin, g/dl, mean & $10.2 \pm 2.0$ & $11.5 \pm 1.8$ & 0.0027 \\
\hline WBC count, $\times 10^{9} / \mathrm{L}$, mean & $10.0 \pm 12.0$ & $9.3 \pm 7.2$ & 0.46 \\
\hline PT in seconds, mean & $11.9 \pm 1.0$ & $12.2 \pm 3.8$ & 0.64 \\
\hline Platelets, $\times 10^{9} / \mathrm{L}$, mean & $276.0 \pm 97.1$ & $272 \pm 130.4$ & 0.68 \\
\hline PTT in seconds, mean & $26.9 \pm 3.3$ & $28.8 \pm 4.7$ & 0.02 \\
\hline
\end{tabular}

Data are numbers of patients (\%) unless otherwise indicated. Means are presented with SDs.

* Other pathologies include melanoma, renal cell, thyroid, sarcoma, heme, neuroblastoma, neuroendocrine, and other (not otherwise specified [NOS]).
TABLE 4. Multivariate analysis of characteristics associated with DVT

\begin{tabular}{lccc}
\hline Characteristic & $\mathrm{OR}^{*}$ & $95 \% \mathrm{Cl}$ & $\mathrm{p} \mathrm{Value}$ \\
\hline Ambulatory & 3.6 & $1.3-9.6$ & 0.010 \\
\hline History of DVT/PE & 4.3 & $1.6-11.6$ & 0.004 \\
\hline PTT & 0.9 & $0.8-1.0$ & 0.020 \\
\hline Hemoglobin & 0.7 & $0.5-0.9$ & 0.008 \\
\hline
\end{tabular}

* Adjusted for all variables in the table. These variables were selected from univariate analyses on the basis of $p<0.05$. The event modeled is DVT.

Among patients in this population who underwent Doppler ultrasound screening, we identified the incidence of preoperative DVT to be $9.48 \%$. As not all patients underwent preoperative screening and there was some suggestion of a selection bias, we performed a rough sensitivity analysis, which provided a range for the preoperative DVT incidence in this population of $7 \%-33.12 \%$.

VTE is a common and morbid perioperative complication. Overall, in the general population, 48 of 100,000 patients develop DVT and 69 of 100,000 patients develop PE yearly. ${ }^{40}$ Among patients undergoing spine surgery, several studies have reported rates of VTE ranging from $1.5 \%$ to $25 \% .{ }^{19,44,48}$ This large variation may be attributed to the breadth of spine procedures involved, ranging from short elective cases to extensive fusions in the setting of trauma or cancer. In spinal deformity surgery, rates of postoperative VTE complications have been reported to be as low as $0.2 \%$ for DVT and PE. ${ }^{36}$ A study of patients with acute traumatic cervical spinal cord injury reported a DVT rate of $10.4 \% .^{29}$ Reported rates of VTE for patients undergoing other types of oncological surgeries range from $0.87 \%$ to $2.83 \% .^{2}$ In this context, the fact that our preoperative DVT incidence of $9.48 \%$ falls within a similar range as postoperative DVT risk in the literature appears to suggest that even prior to surgery, patients with metastatic spine disease suffer higher rates of VTE due to underlying malignancy. This may be explained in part by the advanced nature of systemic disease in patients with metastatic epidural spinal disease. Cancer patients are often deconditioned, neurologically impaired, and have chronic pain, which limits their ability to ambulate, thereby increasing their risk for thromboembolic complications. However, our postoperative DVT and PE rates ( $4.1 \%$ and $1.3 \%$, respectively), fall in the middle or low end of the reported range of VTE risk and are therefore lower than one might expect given the preoperative rates. This discrepancy could be related to the fact that our screening may identify some DVTs prior to surgery that may otherwise eventually have been diagnosed as postoperative DVT. Furthermore, postoperative Doppler ultrasound screening was not performed for all patients. Therefore, the small sample size and the prophylactic measures used to prevent VTE may have effectively underestimated and/ or limited the risk of postoperative DVT observed in this study.

In patients undergoing surgery for spinal metastasis, we have identified ambulatory status as a significant risk factor for a positive finding on preoperative DVT screening. 
Screening for DVT was positive in $24 \%$ of nonambulatory patients, demonstrating a 4-fold higher rate of DVT as compared with the ambulatory patient population. While our study demonstrates ambulatory status as a risk for preoperative DVT, other studies have identified ambulatory status as a risk for postoperative DVT. Dermody et al. examined the rate of DVT in the hospitalized, nonambulatory, neurosurgical patient population and found a postoperative DVT rate of $23 \% .{ }^{17}$ Furthermore, Tominaga et al. identified preoperative walking disability as the largest risk factor for postoperative DVT in patients undergoing spine surgery (OR 4.8, $\mathrm{p}=0.025) \cdot{ }^{44}$ Given the findings of our study, there is a possibility that a proportion of the DVTs identified in these studies may actually have occurred prior to surgery. Furthermore, the significance of ambulation as a risk for DVT is underscored by the fact that even in acutely ill nonsurgical patients, nonambulatory status has been identified as a crucial risk factor for DVT $(19.7 \%$ vs $10.7 \%){ }^{3}$

Relative to craniotomy, spine interventions have typically been thought to entail a lower risk of DVT (7.7\% vs $1.5 \%$, respectively). ${ }^{19}$ Given this assumption, routine DVT screening has not been recommended in the spine surgery population and, therefore, the literature lacks data on baseline VTE risk for these patients. Further confounding this lack of data is the fact that patients with metastatic spine cancer represent an exquisitely high-risk group who harbor a myriad of baseline factors rendering them hypercoagulable and susceptible to VTE formation. Our study provides useful information on the risk factors in this population, primarily identifying the foremost risk factor as preoperative ambulatory status. Nonambulatory patients not only suffer increased risk for postoperative DVT, but also increased rates of preoperative DVT. Whether patients truly benefit from or require prophylactic IVC filter placement or other interventions for these preoperative DVTs prior to surgery remains to be determined and cannot be accurately assessed by our retrospective analysis.

In addition, a previous history of DVT or PE was strongly associated with screening positive for a preoperative DVT. Unsurprisingly, this indicates that a history of prior DVT or PE is a significant risk factor for screening positive for preoperative DVT. This finding is consistent with widely accepted knowledge of prior DVT as a risk factor for recurrence ${ }^{4}$ in the postoperative setting after spine surgery. ${ }^{10,38}$

Furthermore, significant differences in PTT (26.9 vs 28.8 seconds, $p=0.02)$ and hemoglobin level (10.2 vs 11.5 $\mathrm{g} / \mathrm{dl}, \mathrm{p}=0.0027$ ) were identified between those who had positive versus negative results on preoperative screening for DVT. Since the PTT values for those with positive or negative results fall within normal limits and are only minimally different, PTT was not considered an important indicator of risk for DVT. Similarly, the difference in hemoglobin level between patients who had positive versus negative results on preoperative screening was small and also not considered an important risk factor for DVT. Hemoglobin level was incorporated into a risk scoring model developed by Khorana et al. to predict thrombosis in ambulatory cancer patients, however this model has not been independently validated. ${ }^{24}$

\section{Ultrasonographic Screening}

Routine preoperative Doppler ultrasound screening was implemented for nearly all patients at our institution who underwent spinal surgery related to a known spine metastasis. Preoperative screening for DVT attempts to mitigate the occurrence of catastrophic VTE, mainly $\mathrm{PE}$, in the postsurgical setting. Screening based on clinical symptoms often underestimates the true prevalence of VTE. ${ }^{31}$ Thus imaging-based screening could be beneficial for the high-risk spine oncology patient population.

The finding that a high percentage $(9.48 \%)$ of patients with metastatic spinal disease suffer preoperative DVT suggests that this population may benefit from routine ultrasound screening. There is currently no consensus on the utility of such a strategy. In the settings of orthopedic and spinal reconstructive surgery, symptomatic PEs arise in both screened and unscreened populations at approximately equal rates. ${ }^{37,41}$ Similarly, PEs arose at nearly similar rates in screened and unscreened trauma victims.,12 However, in a study of a large trauma population where aggressive routine DVT screening and prophylaxis were instituted, clinicians were able to achieve low rates of PE $(0.7 \%)$ compared with reported data. ${ }^{1}$

In our study, 4 PEs occurred in the screened population $(4 / 234,1.7 \%)$ and none in the unscreened population $(0 / 80,0 \%)$, suggesting that screening was not successful in preventing VTE. The rates of PE after surgery vary by surgery type, ranging from $0.4 \%$ for gastric surgery to $2.2 \%$ for spinal surgery. ${ }^{2,15,46}$ The overall rate of PE in our population was $1.3 \%$, lower than comparative historically reported rates. Therefore, our data are ambiguous with regard to the efficacy of DVT screening, and future studies will need to prospectively test the true benefits of preoperative screening.

The efficacy of a routine preoperative DVT screening strategy relies on the success of IVC filter placement. Of the 22 patients who were diagnosed with a preoperative DVT and had a successful IVC filter placement, only 1 went on to develop PE (4.5\%). It has been reported that among patients with a calf DVT, $10 \%$ will go on to develop a symptomatic PE. ${ }^{30}$ The reduced rate of $4.5 \%$ DVT progression to $\mathrm{PE}$ in our study suggests that placement of an IVC filter may be an effective prophylactic measure, but this study was not powered to validate this conclusion in our patient population. The efficacy of IVC filter placement varies by setting. In a population-based study looking at all hospital discharges, IVC filter placement did not reduce readmissions for PE. ${ }^{47}$ However, among highrisk patients, such as patients with proximal DVT, ${ }_{16}^{16}$ severe trauma patients with DVT, ${ }^{34}$ and patients with DVT undergoing spinal surgery, ${ }^{14,27}$ IVC filter placement is consistently associated with reduced rates of PE. Thus, for highrisk patients, IVC filter placement may offer an effective prophylactic measure.

Of the 4 patients who developed postoperative PE, 3 had negative results on preoperative screening for DVT. The absence of DVT in patients who went on to develop PE possibly occurred because 1) a DVT developed after preoperative screening, 2) the sensitivity of Doppler ultrasound was insufficient for detection of occult DVTs, ${ }^{23}$ and/or 3) the thrombosis developed outside of the femoral/ 
popliteal system. Regardless, the fact that 3 of 4 patients who developed PE had negative screening results and the fourth patient, who had positive results on screening, developed a PE despite prophylactic IVC filter placement indicates that preoperative screening cannot always prevent VTE. Furthermore, a recent study examining the utility of lower-extremity ultrasound screening for DVT in trauma patients found that increased screening was associated with higher rates of DVT but not with higher rates of PE. ${ }^{18}$ The authors concluded that aggressive screening protocols in trauma patients may detect clinically insignificant DVT that does not require intervention. While we have a low threshold to perform VTE screening postoperatively, it is not routinely performed in all patients. Accordingly, we did not pursue a thorough evaluation of postoperative VTE incidence, and the postoperative VTE rate of $4.1 \%$ is likely an underestimation of the true incidence. Given this limitation, we did not feel that a statistical analysis of variables associated with postoperative VTE was appropriate.

Whether screening is an effective strategy for prevention of catastrophic VTE in spine surgery patients with spinal metastases will require further study. Although routine screening is low cost and low risk, the cost-effectiveness of such a strategy varies by hospital and patient setting. ${ }^{20,22,43}$ Perhaps targeted screening of populations at very high risk, such as nonambulatory patients, could reduce screening while focusing on those patients most likely to benefit. ${ }^{21}$

\section{Study Limitations}

Prior to the start of the study period, preoperative ultrasonographic screening for DVT became the intended standard of care within our practice. While ultrasonographic screening was attempted for nearly all patients, only 232 of a total of 314 patients were screened during the analysis period. We felt it important to include the consecutive cohort of patients, including the unscreened group, to provide as representative an estimate of VTE risk as possible. Although selection for screening was not felt to inherently represent intentional or systematic bias (i.e., those who were not screened were not chosen, but rather did not undergo screening due to logistic issues), the older age of the screened versus unscreened patients suggests that there may have been a nonsystematic selection bias. Given the equivalence of other baseline characteristics between the screened and unscreened groups (see Table 2), we do not believe that selection bias substantively affects the findings of this series. Furthermore, it is possible that some unscreened patients presented more urgently with less time available for comprehensive preoperative management than their screened counterparts. However, it may also be possible that screened patients had other comorbidities or risk factors that skewed clinicians to obtain an ultrasonographic screening examination. If such a systematic bias exists, it is possible that we have self-selected a higher-risk cohort that was screened preoperatively for DVT, resulting in an effectively higher than true incidence of VTE. One must, therefore, exercise caution when extrapolating from our VTE rates for a given population. We are also limited in our ability to accurately compare our rates of DVT to other rates reported in the literature due to the varied screening procedures used by different groups, such as tracking D-dimer levels, frequent ultrasonographic screening, or no screening at all. Lastly, we did not explore additional hypercoagulable states that may contribute to VTE risk, such as factor V Leiden and prothrombin G20210A as these are relatively rare (present in approximately $1 \%-7 \%$ of the population) and not routinely documented or screened for in the medical record.

Due to the retrospective nature of this study, the collected data were limited to those recorded in the electronic health record. Because of the importance to this study's conclusion, it should be noted that data collected on patients' preoperative ambulatory status was limited to any assessment of walking ability. Furthermore, we did not abstract data on improvement in postoperative functional or ambulatory status. The sensitivity of Doppler ultrasound screening is high $(92 \%-95 \%)$ in symptomatic patients, ${ }^{45}$ however its sensitivity is far lower in asymptomatic patients. ${ }^{23}$ Since our patients were largely asymptomatic, our study might be limited by the low sensitivity of Doppler ultrasound screening for this population.

\section{Conclusions}

We present the first clinical investigation evaluating the incidence of preoperative VTE in patients with spinal metastases to our knowledge. After analyzing a consecutive series of 314 patients who underwent spinal surgery for management of metastatic disease, we identified a $9.48 \%$ incidence of preoperative DVT. Nonambulatory patients suffered a 4-fold increased rate of positive results of screening for preoperative DVT as compared with ambulatory patients. As such, our data confirms that the patients undergoing surgery for spinal metastases are at high risk for VTE. Given this, we believe that the use of targeted preoperative ultrasonographic screening of patients should continue to be assessed to determine whether it can decrease postoperative morbidity and mortality from VTE in this population.

\section{Acknowledgments}

This study was supported by National Cancer Institute Center Core Grant No. P30 CA008748.

\section{References}

1. Adams RC, Hamrick M, Berenguer C, Senkowski C, Ochsner MG: Four years of an aggressive prophylaxis and screening protocol for venous thromboembolism in a large trauma population. J Trauma 65:300-308, 2008

2. Agnelli G, Bolis G, Capussotti L, Scarpa RM, Tonelli F, Bonizzoni E, et al: A clinical outcome-based prospective study on venous thromboembolism after cancer surgery: the @RISTOS project. Ann Surg 243:89-95, 2006

3. Amin AN, Girard F, Samama MM: Does ambulation modify venous thromboembolism risk in acutely ill medical patients? Thromb Haemost 104:955-961, 2010

4. Anderson FA Jr, Spencer FA: Risk factors for venous thromboembolism. Circulation 107 (23 Suppl 1):I9-I16, 2003

5. Bach F, Larsen BH, Rohde K, Børgesen SE, Gjerris F, BøgeRasmussen T, et al: Metastatic spinal cord compression. Occurrence, symptoms, clinical presentations and prognosis in 
398 patients with spinal cord compression. Acta Neurochir (Wien) 107:37-43, 1990

6. Barron KD, Hirano A, Araki S, Terry RD: Experiences with metastatic neoplasms involving the spinal cord. Neurology 9:91-106, 1959

7. Borer DS, Starr AJ, Reinert CM, Rao AV, Weatherall P, Thompson D, et al: The effect of screening for deep vein thrombosis on the prevalence of pulmonary embolism in patients with fractures of the pelvis or acetabulum: a review of 973 patients. J Orthop Trauma 19:92-95, 2005

8. Brambilla S, Ruosi C, La Maida GA, Caserta S: Prevention of venous thromboembolism in spinal surgery. Eur Spine J 13:1-8, 2004

9. Cerrato D, Ariano C, Fiacchino F: Deep vein thrombosis and low-dose heparin prophylaxis in neurosurgical patients. J Neurosurg 49:378-381, 1978

10. Charen DA, Qian ET, Hutzler LH, Bosco JA: Risk factors for postoperative venous thromboembolism in orthopaedic spine surgery, hip arthroplasty, and knee arthroplasty patients. Bull Hosp Jt Dis (2013) 73:198-203, 2015

11. Chew HK, Wun T, Harvey D, Zhou H, White RH: Incidence of venous thromboembolism and its effect on survival among patients with common cancers. Arch Intern Med 166:458464, 2006

12. Cipolle MD, Wojcik R, Seislove E, Wasser TE, Pasquale MD: The role of surveillance duplex scanning in preventing venous thromboembolism in trauma patients. J Trauma 52:453-462, 2002

13. Cohoon KP, Leibson CL, Ransom JE, Ashrani AA, Park MS, Petterson TM, et al: Direct medical costs attributable to venous thromboembolism among persons hospitalized for major operation: a population-based longitudinal study. Surgery 157:423-431, 2015

14. Dazley JM, Wain R, Vellinga RM, Cohen B, Agulnick MA: Prophylactic inferior vena cava filters prevent pulmonary embolisms in high-risk patients undergoing major spinal surgery. J Spinal Disord Tech 25:190-195, 2012

15. Dearborn JT, Hu SS, Tribus CB, Bradford DS: Thromboembolic complications after major thoracolumbar spine surgery. Spine (Phila Pa 1976) 24:1471-1476, 1999

16. Decousus H, Leizorovicz A, Parent F, Page Y, Tardy B, Girard P, et al: A clinical trial of vena caval filters in the prevention of pulmonary embolism in patients with proximal deep-vein thrombosis. Prévention du Risque d'Embolie Pulmonaire par Interruption Cave Study Group. N Engl J Med 338:409-415, 1998

17. Dermody M, Alessi-Chinetti J, Iafrati MD, Estes JM: The utility of screening for deep venous thrombosis in asymptomatic, non-ambulatory neurosurgical patients. J Vasc Surg 53:1309-1315, 2011

18. Dietch ZC, Edwards BL, Thames M, Shah PM, Williams MD, Sawyer RG: Rate of lower-extremity ultrasonography in trauma patients is associated with rate of deep venous thrombosis but not pulmonary embolism. Surgery 158:379-385, 2015

19. Flinn WR, Sandager GP, Silva MB Jr, Benjamin ME, Cerullo LJ, Taylor M: Prospective surveillance for perioperative venous thrombosis. Experience in 2643 patients. Arch Surg 131:472-480, 1996

20. Goodacre S, Sampson F, Stevenson M, Wailoo A, Sutton A, Thomas S, et al: Measurement of the clinical and cost-effectiveness of non-invasive diagnostic testing strategies for deep vein thrombosis. Health Technol Assess 10:1-168, iii-iv, 2006

21. Harris LM, Curl GR, Booth FV, Hassett JM Jr, Leney G, Ricotta JJ: Screening for asymptomatic deep vein thrombosis in surgical intensive care patients. J Vasc Surg 26:764-769, 1997

22. Jawa RS, Warren K, Young D, Wagner M, Nelson L, Yetter
D, et al: Venous thromboembolic disease in trauma and surveillance ultrasonography. J Surg Res 167:24-31, 2011

23. Jongbloets LM, Lensing AW, Koopman MM, Büller HR, ten Cate JW: Limitations of compression ultrasound for the detection of symptomless postoperative deep vein thrombosis Lancet 343:1142-1144, 1994

24. Khorana AA, Kuderer NM, Culakova E, Lyman GH, Francis CW: Development and validation of a predictive model for chemotherapy-associated thrombosis. Blood 111:4902-4907, 2008

25. Laufer I, Rubin DG, Lis E, Cox BW, Stubblefield MD, Yamada Y, et al: The NOMS framework: approach to the treatment of spinal metastatic tumors. Oncologist 18:744751,2013

26. Lee AY, Levine MN: Venous thromboembolism and cancer: risks and outcomes. Circulation 107 (23 Suppl 1):I17-I21, 2003

27. Leon L, Rodriguez H, Tawk RG, Ondra SL, Labropoulos $\mathrm{N}$, Morasch MD: The prophylactic use of inferior vena cava filters in patients undergoing high-risk spinal surgery. Ann Vasc Surg 19:442-447, 2005

28. Levitan N, Dowlati A, Remick SC, Tahsildar HI, Sivinski LD, Beyth R, et al: Rates of initial and recurrent thromboembolic disease among patients with malignancy versus those without malignancy. Risk analysis using Medicare claims data. Medicine (Baltimore) 78:285-291, 1999

29. Masuda M, Ueta T, Shiba K, Iwamoto Y: D-dimer screening for deep venous thrombosis in traumatic cervical spinal injuries. Spine J 15:2338-2344, 2015

30. Negus D, Pinto DJ: Natural history of postoperative deepvein thrombosis. Lancet 2:645, 1969

31. Ottinger H, Belka C, Kozole G, Engelhard M, Meusers P, Paar D, et al: Deep venous thrombosis and pulmonary artery embolism in high-grade non Hodgkin's lymphoma: incidence, causes and prognostic relevance. Eur J Haematol 54:186-194, 1995

32. Patchell RA, Tibbs PA, Regine WF, Payne R, Saris S, Kryscio RJ, et al: Direct decompressive surgical resection in the treatment of spinal cord compression caused by metastatic cancer: a randomised trial. Lancet 366:643-648, 2005

33. Rickles FR, Levine MN: Epidemiology of thrombosis in cancer. Acta Haematol 106:6-12, 2001

34. Rogers FB, Shackford SR, Wilson J, Ricci MA, Morris CS: Prophylactic vena cava filter insertion in severely injured trauma patients: indications and preliminary results. J Trauma 35:637-642, 1993

35. Salmaggi A, Simonetti G, Trevisan E, Beecher D, Carapella CM, DiMeco F, et al: Perioperative thromboprophylaxis in patients with craniotomy for brain tumours: a systematic review. J Neurooncol 113:293-303, 2013

36. Sansur CA, Smith JS, Coe JD, Glassman SD, Berven SH, Polly DW Jr, et al: Scoliosis research society morbidity and mortality of adult scoliosis surgery. Spine (Phila Pa 1976) 36:E593-E597, 2011

37. Schmidt B, Michler R, Klein M, Faulmann G, Weber C, Schellong S: Ultrasound screening for distal vein thrombosis is not beneficial after major orthopedic surgery. A randomized controlled trial. Thromb Haemost 90:949-954, 2003

38. Schulte LM, O'Brien JR, Bean MC, Pierce TP, Yu WD, Meals C: Deep vein thrombosis and pulmonary embolism after spine surgery: incidence and patient risk factors. Am J Orthop 42:267-270, 2013

39. Sciubba DM, Gokaslan ZL: Diagnosis and management of metastatic spine disease. Surg Oncol 15:141-151, 2006

40. Silverstein MD, Heit JA, Mohr DN, Petterson TM, O'Fallon WM, Melton LJ III: Trends in the incidence of deep vein thrombosis and pulmonary embolism: a 25 -year populationbased study. Arch Intern Med 158:585-593, 1998

41. Smith MD, Bressler EL, Lonstein JE, Winter R, Pinto MR, 
Denis F: Deep venous thrombosis and pulmonary embolism after major reconstructive operations on the spine. A prospective analysis of three hundred and seventeen patients. J Bone Joint Surg Am 76:980-985, 1994

42. Sørensen HT, Mellemkjaer L, Olsen JH, Baron JA: Prognosis of cancers associated with venous thromboembolism. N Engl J Med 343:1846-1850, 2000

43. Sud S, Mittmann N, Cook DJ, Geerts W, Chan B, Dodek P, et al: Screening and prevention of venous thromboembolism in critically ill patients: a decision analysis and economic evaluation. Am J Respir Crit Care Med 184:1289-1298, 2011

44. Tominaga H, Setoguchi T, Tanabe F, Kawamura I, Tsuneyoshi Y, Kawabata N, et al: Risk factors for venous thromboembolism after spine surgery. Medicine (Baltimore) 94:e466, 2015

45. White RH, McGahan JP, Daschbach MM, Hartling RP: Diagnosis of deep-vein thrombosis using duplex ultrasound. Ann Intern Med 111:297-304, 1989

46. White RH, Romano PS, Zhou H, Rodrigo J, Bargar W: Incidence and time course of thromboembolic outcomes following total hip or knee arthroplasty. Arch Intern Med 158:1525-1531, 1998

47. White RH, Zhou H, Kim J, Romano PS: A population-based study of the effectiveness of inferior vena cava filter use among patients with venous thromboembolism. Arch Intern Med 160:2033-2041, 2000

48. Yoshioka K, Kitajima I, Kabata T, Tani M, Kawahara N, Murakami $\mathrm{H}$, et al: Venous thromboembolism after spine sur- gery: changes of the fibrin monomer complex and D-dimer level during the perioperative period. J Neurosurg Spine 13:594-599, 2010

\section{Disclosures}

Dr. Laufer reports consultant relationships with SpineWave, Globus, and DePuy Synthes.

\section{Author Contributions}

Conception and design: Bilsky, Laufer. Acquisition of data: Kahn, Hijazi. Analysis and interpretation of data: Bander, Cederquist, Cope, Reiner. Drafting the article: Zacharia. Administrative/technical/material support: McLaughlin. Study supervision: Bilsky.

\section{Supplemental Information}

\section{Previous Presentations}

A portion of this study was presented at the annual meeting of the Congress of Neurological Surgeons in New Orleans, Louisiana, September 26-30, 2015 .

\section{Correspondence}

Mark Bilsky, Department of Neurosurgery, Memorial Sloan Kettering Cancer Center, 1275 York Ave., New York, NY 10065. email: bilskym@mskcc.org. 